\title{
Relationship Between Protein Oxidation Markers and Oxidative Stress Biomarkers
}

\author{
Silvia Clara Kivatinitz \\ Dept. Química Biológica, Fac. Ciencias Químicas, \\ Universidad Nacional de Córdoba, Ciquibic-Conicet, \\ Argentina
}

\section{Introduction}

There is a general agreement (belief) that lipids are the pivotal element in inflammatory disease. One of the most studied topics is the connection between lipid oxidation and cardiovascular disease. In a very recent review, the introductory paragraphs states, after resuming the elements of the inflammatory response starting with stimulated endothelium displaying adhesive molecules for circulating leucocytes, lipid oxidation products formed by virtually every vascular cell type participate in orchestrating these processes and the inflammatory process is actively limited by activation of a resolution phase, often via generation of structurally specific oxidized lipids whose function is to orchestrate resolution of inflammation (McIntyre \& Hazen 2010).

Most of the knowledge involving lipid oxidation comes from "in vitro" studies and on supplementation trials with antioxidants like vitamins and anti-inflammatory drugs. Vitamins $\mathrm{E}$ and $\mathrm{C}$ are considered dietary antioxidants although mostly ex vivo measurements of lipid peroxidation have been performed (Hillstrom et al. 2003; Heinecke 2001). Quantifying "in vivo" lipid oxidation is not easy and several biomarkers of lipid peroxidation has been used like F2-isoprostanes, considered the most accurate way to measure oxidative stress "in vivo", and as a risk factor for atherosclerosis and other diseases (Lawson et al. 1999).

The secondary products of lipid peroxidation (LPO) the reactive carbonyl compounds, modify biologically essential molecules such as proteins and DNA bases (Yuan et al. 2006). Thus lipid oxidation processes in biological tissues may be more complicated since they contain a plethora of carbohydrates, proteins and lipids forming a complex matrix. In tissues, lipid oxidation can cause protein oxidation due to close interactions between lipids and proteins. LPO "in vivo" has been implicated as the underlying mechanisms in numerous disorders and diseases such as cardiovascular diseases, cancer, neurological disorders, and aging.

Thus, when oxidative stress biomarkers are evaluated protein oxidation deserves consideration.

\section{Protein oxidation}

In the next paragraphs I will analyze several works about protein oxidation "in vitro" (incubation in test tubes, cells systems, perfusion, foods) and "in vivo" (disease epidemiology and animal models mostly) with the intention of stressing similarities and differences between them. The next table is an outline of the literature reviewed in points 2.1 and 2.2. 


\section{Protein oxidation "in vitro"}

(Batthyány et al. 2000)

(Yang et al. 1997)

(Hedrick et al. 2000)

(Chantepie et al. HDL treated with HOCL 2009)

(Sigalov \& Stern 2001)

(Chen et al. 2007)

Copper binding to apolipoprotein B-100 is necessary for oxidation

LDL treated with HOCL

Incubation of HDL under oxidized apo A-I

\section{Characteristis of the model employed} hyperglycaemic conditions

Reconstituted HDL containing

Polyphenolics in the $\mathrm{Cu}(2+)-$ induced generation of conjugated dienes of LDL

(Arai \& Nakamura VLDL oxidation induced by 2004) peroxyl radicals and peroxynitrite

(Jedidi et al. 2003) LDL oxidation was mediated by water gamma radiolysis

(Roland et al. $\quad$ LDL and $\mathrm{Cu}(2+)$ 2001)

(Patterson et al. 2003)

(Makedou et al. 2009)

(Hockerstedt et al. Copper-induced oxidation of 2004) purified HDL and hydroperoxide or $\mathrm{Cu}(2+)$ Copper-induced Low-density

\section{Main observation}

Formation of protein-tryptophanyl radicals

Selective process of modification of apoB-100 by HOCL

Changes in HDL caused by hyperglycaemia contribute to accelerated atherosclerosis

Small, dense HDL less susceptible to oxidative modification

Destabilization of the oxidized protein to denaturation

Polyphenolics reduce oxidation of apoB-100

Ascorbic acid protects apolipoprotein E of oxidation

$\left.{ }^{*}\right) \mathrm{OH}$ initiate oxidation leading to apob carbonylation in presence of aminoguanidine

Flavonoids myricetin, quercetin, and catechin decreased copper binding to LDL

Low $\mathrm{Cu}(2+)$ inhibit tocopherol induced oxidation in LDL, promote breakdown of lipid hydroperoxides into radicals lipoprotein (LDL) oxidizability for hyperlipidemia have increased LDL susceptibility to oxidation

LCAT causes estradiol esterification and thus provide antioxidant protection to HDL

(Moreno \& Fuster LDL oxidation susceptibility to 2004) $\mathrm{Cu}(2+)$

(Popa et al. 2009) HDL ability to inhibit copperinduced oxidation of lowdensity lipoprotein (LDL)

(Deakin et al. 2002)
Apolipoprotein E polymorphism partially explain differences in individual responses to diet Infliximab has beneficial effects on lipids through changes in HDL antioxidative capacity Accumulation of PON1 in cell membrane was not influenced by the ability of the cell to co-secrete of apoA-I
Transfection of $\mathrm{CHO}$ cells, did not co-secretate apo A-I and lipids leading to formation of 
HDL-like complexes

(Allen \& Jandeleit- Review

Dahm 2005)

(Shao et al. 2010) Revision

(Obama et al. Copper-induced oxLDL 2007)

(Suc et al. 2003) Tyrosylation of high-density lipoprotein
Recognised metabolic abnormalities upregulation of advanced glycation endproducts, renin-angiotensin system, oxidative stress associated with diabetes Biochemical studies implicated tyrosine chlorination and methionine oxygenation in the loss of ABCA1 and LCAT activity by oxidized apoA-I Histidine residue modified by 4hydroxynonenal, a major lipid peroxidation product, oxidized histidine and tryptophan residues HDLT competes with oxidized and acetylated LDL, ligands of scavenger receptor class $B$ type I/II

(Zarev et al. 2002) LDL oxidation induced in vitro Apolipoprotein B carbonylated by copper and ${ }^{*} \mathrm{OH} / \mathrm{O}^{*}(2)(-)$ free radicals generated by gamma-radiolysis fragmentation not detected during the lag phase of copper-oxidized LDL but detected during the propagation phase

(Edelstein et al. Oxidation of LDL by $\mathrm{Cu}(2)+$ or Apo[a] but not apoB-100 resists 2001) the combined phospholipase A2 and lipoxygenase system

(Gao et al. 2008) Copper and hypochlorite (prefer'-entially oxidize lipids or proteins, respectively) oxidation of HDL

(Gomes et al. 2002) Beta 2-Glycoprotein I (beta 2 GPI), macrophage uptake of particles with phosphatidylserine containing surfaces, and unilamellar vesicles

(Jolivalt et al. 2000) Myeloperoxidase oxidative system

(Van Antwerpen et al. 2006; Van

LDL oxidation by myeloperoxidase

Antwerpen et al.

2005)

\section{Protein oxidation Characteristis of the model "in vivo" employed}

(Hershfield et al. Erythrocytes 2010)

(Janatuinen et al. Young adults with Type 1 oxidative fragmentation, apoB-100 can be degraded by enzymes and oxidation Mild oxidation favor HDL remodeling due to diminished apolipoprotein affinity for lipids due to oxidation of methionine and aromatic residues Particle uptake in the presence of beta 2 GPI is coupled to an inhibition of reactive species production by liver macrophagest

Oxidation of apo E decreases its incorporation into phospholipid discs by approximately $50 \%$

Thiol-containing molecules such as glutathione, captopril, and Nacetylcysteine (NAC) and its lysinate salt (NAL)

\section{Main observation}

Urate is not a major factor controlling oxidative stress in vivo

Pravastatin decreased LDL oxidation; 
2004)

Diabetes

(Zhang et al. 2002) A model of inflammation (peritonitis) with MPO knockout mice (MPO-/-)

(Seshadri et al. Transfected HepG2 2002)

(Yoshida \& Kisugi Review 2010)

(Allen \& Jandeleit- Review Dahm 2005)

(Erciyas et al. Children with type 1 diabetes 2004) mellitus

(Candore et al. Review 2010)

(Bassett \& Review

Montine 2003)

(Shao et al. 2008) Incubation of oxidized HDL and LCAT

(Haberland et al. 1988)

(Palinski et al. Rabbit and human 1989) hyperlipidemic rabbits
Watanabe heritable

(Artola et al. 1997) Hypercholesterolemic chickens without improvement in myocardial perfusion

MPO-dependent formation of NOderived oxidants, and not tyrosyl radical, serve as a preferred pathway for initiating lipid peroxidation.

Insulin functions as a bidirectional, condition-dependent regulator of hepatic cell Ceruloplasmin expression, reflecting its dual roles in inflammation Several pathways are involved in the promotion of LDL oxidation in vitro and in vivo, but the physiologically relevant mechanisms of LDL oxidation are still imperfectly understood Glycation endproducts, reninangiotensin system, oxidative stress and increased expression of growth factors and cytokines have been observed in the setting of diabetes

Relationship between the lipid profile and oxidative stress

Cholesterol, oxidative stress and related therapeutic possibilities, i.e., nonsteroidal antiinflammatory drugs, immunotherapy, diet, and curcumin ApoE isoforms may specifically influence the cellular distribution of lipid peroxidation products in brain

Oxidation of a single Met in apoa-I in impaired LCAT activation, a critical early step in reverse cholesterol transport Presence of protein modified by malondialdehyde which colocalizes with the extracellular deposition of apolipoprotein B-100

Autoantibodies against malondialdehyde-LDL (titers from 512 to greater than 4096) can be demonstrated in sera HDL from treated animals was more peroxidized, had higher amount of oligomeric apoA-I, than that of control 
animals

(Ónody et al. 2003) Rat experimental hyperlipidemia

(Ueno et al. 2002)

(Wiggin et al. 2008)

Diabetic Akita mice Streptozotocin-treated DBA/2J mice
Induced hyperlipidemia leads to an increase in cardiac ONOO- formation and a decrease of $\mathrm{NO}$ and deterioration of cardiac performance

Hyperglycemia induced oxidative stress

Rosiglitazone treatment did not affect hyperglycemia but did reduce oxidative stress and prevented the development of thermal hypoalgesia

Table 1. Bibliography reviewed about protein oxidation "in vitro" and "in vivo".

\section{1 "In vitro" protein oxidation}

The oxidation of lipoproteins has been studied in diverse "in vitro" systems using several experimental approaches i.e.; cupric ion (Batthyány et al. 2000), HOCl (Yang et al. 1997) or glycation mimicking diabetic conditions (Hedrick et al. 2000). More complex systems using "in vitro" cells systems had also been used.

Protein becomes modified during oxidation, resulting in a change in the protein conformation and degradation of amino acids, e.g., tryptophan and tyrosine (Batthyány et al. 2000), or amine groups (Chantepie et al. 2009) or methionine (Sigalov \& Stern 2001). Different subclasses of lipoproteins, which differ in size or charge, have been shown to display different susceptibility to "in vitro" oxidation (Chantepie et al. 2009; Chen et al. 2007). Both apolipoprotein-B and apolipoprotein-A has been subjected to several oxidation processes and structural, chemical and biological functions alterations reported. Also, the effect of several antioxidants such as vitamins (Arai \& Nakamura 2004), polyphenolic compounds (Chen et al. 2007) and inhibitors of glycation (Jedidi et al. 2003) has been reported.

Copper has been often used to oxidize LDL (low density lipoprotein) in experiments "in vitro" and was proposed as a candidate for oxidizing LDL in atherosclerotic lesions. Copper ions bind to LDL being the copper-binding capacity progressively and markedly higher when LDL is increasingly oxidized. It was assessed that the flavonoids myricetin, quercetin, and catechin (but not epicatechin, kaempferol, or morin), at concentrations equimolar to the copper present significantly decreased copper binding to LDL (Roland, Patterson, \& Leake 2001). Later, the same group proposed uric acid as both antioxidant and prooxidant for LDL. They suggested that reduction of $\mathrm{Cu}^{+2}$ to $\mathrm{Cu}^{+}$was behind the effects observed since the decreased concentration of $\mathrm{Cu}^{+2}$ would inhibit tocopherol-mediated peroxidation in native LDL, and the generation of $\mathrm{Cu}^{+}$would promote the rapid breakdown of lipid hydroperoxides in mildly oxidized LDL into lipid radicals (Patterson, Horsley, \& Leake 2003). These, other "in vitro" observations and the high plasma urate concentration, related to loss of urate oxidase in evolution, are postulated to protect humans from oxidative injury. This hypothesis has broad clinical relevance, but support rests largely on "in vitro" data and epidemiologic associations. Recently, "in vivo" evidence seems to deny such a physiological or pathological role. Therapy with infusion of PEGylated recombinant porcine urate oxidase generates $\mathrm{H}_{2} \mathrm{O}_{2}$ while depleting urate. Oxidative stress was monitored with F2-Isoprostanes (F2-IsoPs) and protein carbonyls (PC), products of arachidonic acid and protein oxidation, in plasma of 26 refractory gout patients receiving infusions of the enzyme. At baseline, urate was markedly elevated in all patients, and plasma F2-IsoP concentration was elevated in 
most. Treatment rapidly lowered urate in all patients, but did not correlate with isoprostanes or protein carbonyls. The authors conclude that urate is not a major factor controlling oxidative stress "in vivo" (Hershfield et al. 2010).

Another interesting aspect of research is the one that deals with the susceptibility of lipoprotein taken from atherosclerotic lesions or from patients receiving pharmacological treatment with anti-inflammatory or hypolipemic drug therapy. For example, it has been found that descendants with a positive family history for cardiovascular disease (CVD) or hyperlipidemia have an atherogenic lipid profile and increased LDL susceptibility to oxidation (Makedou et al. 2009).

Also it has been suggested that endogenous estrogens protect against atherosclerosis by inhibition of lipoprotein oxidation. To act as antioxidants, estrogens need to be converted to lipophilic estrogen fatty acyl esters in a reaction catalyzed by lecithin: cholesterol acyltransferase (LCAT) (Hockerstedt, Jauhiainen, \& Tikkanen 2004). Another hint linking LDL oxidative status and disease is the association between apolipoprotein $\mathrm{E}$ gene promoter polymorphism $(-219 \mathrm{G} \rightarrow \mathrm{T})$ has been with increased risk of myocardial infarction, premature coronary artery disease, and decreased plasma apolipoprotein $\mathrm{E}$ concentrations. The presence of the $\mathrm{T}$ allele in the apolipoproteinE $-219 \mathrm{G} \rightarrow \mathrm{T}$ polymorphism increases the susceptibility of plasma LDL to oxidative modifications and enhances the response of apolipoprotein B and LDL cholesterol to the presence of saturated fat in the diet of healthy men (Moreno et al. 2004).

In Rheumatoid Arthritis (RA) patients, another disease of inflammatory etiology, effects of tumor necrosis factor (TNF) on the antioxidative capacity of HDL has been investigated and it was observed that has beneficial effects on lipids through changes in HDL (high density lipoprotein) antioxidative capacity, which might be clinically relevant and contribute to the reported protective effect of anti-TNF on cardiovascular morbidity in Rheumatoid Arthritis (Popa et al. 2009). This observation emphasizes the importance of HDL antiatherogenic capacity for cardiovascular risk in chronic inflammatory conditions.

Lipoproteins are very heterogeneous particles that contain several active enzymes and interact with other circulating proteins. Several of the these intrinsic or interacting enzymes have oxidative or antioxidative functions, e. g., paraoxonase-1 (Deakin et al. 2002), reninangiotensin system (Allen \& Jandeleit-Dahm 2005), or myeloperoxidase (Shao et al. 2010). Most interestingly, changes in the interaction between apolipoprotein and shell lipids has been shown to occur when HDL or LDL were subject to oxidation "in vitro" (Obama et al. 2007; Suc et al. 2003; Zarev et al. 2002). These changes in lipid protein interaction seem to be of importance for the biological function and receptor binding (Edelstein et al. 2001; Gao, Jayaraman, \& Gursky 2008; Gomes et al. 2002; Hedrick et al. 2000). One example of the alteration in lipid-protein interaction was obtained using the myeloperoxidase (MPO) oxidative system. The researchers reported that oxidation of the three recombinant apolipoprotein E isoforms was differential, with apolipoprotein E4 being more susceptible than apolipoprotein E3, which in turn is much more susceptible than apolipoprotein E2 and that oxidation of apolipoprotein $\mathrm{E}$ decreases its incorporation into phospholipid discs (Jolivalt et al. 2000). LDL was also modified by MPO "in vitro" and by thiol-containing molecules as glutathione, captopril, and $\mathrm{N}$-acetylcysteine has been shown to act as antioxidants (Van Antwerpen et al. 2005; Van Antwerpen et al. 2006). The ability of MPO to initiate lipid peroxidation "in vivo" and its role in generating bioactive eicosanoids during inflammation has been explored using a model of inflammation (peritonitis) with MPO 
knockout mice (MPO-/-). Peritonitis-triggered formation of F2-isoprostanes, a marker of oxidant stress "in vivo" and was reduced by $85 \%$ in the MPO-/- mice. Parallel analyses of peritoneal lavage proteins for protein dityrosine and nitrotyrosine, molecular markers for oxidative modification by tyrosyl radical and $\cdot \mathrm{NO}_{2}$, respectively, revealed marked reductions in the content of nitrotyrosine, but not dityrosine, in MPO-/-samples. Thus, MPO serves as a major enzymatic catalyst of lipid peroxidation at sites of inflammation. Moreover, MPO-dependent formation of $\cdot \mathrm{NO}^{-}$derived oxidants, and not tyrosyl radical, appears to serve as a preferred pathway for initiating lipid peroxidation and promoting oxidant stress "in vivo" (Zhang et al. 2002). These findings indicate that the proposed role of MPO in dityrosine cross-linking were erroneous and suggest that alternative mechanisms participate in dityrosine formation in this model, such as protein-bound redox active transition metal ions, and ceruloplasmin (Seshadri, Fox, \& Mukhopadhyay 2002).

\section{2 "In vivo" protein oxidation}

There are many reports that relate diseases caused by oxidative imbalance with characteristic features of oxidized protein "in vivo". Many lines of evidence suggest that oxidized LDL is implicated in the pathogenesis of atherosclerotic vascular diseases (Yoshida \& Kisugi 2010), in diabetes (Allen \& Jandeleit-Dahm 2005; Erciyas et al. 2004), Alzheimer (Candore et al. 2010; Bassett \& Montine 2003) .

Recently, it has been demonstrated that HDL isolated from patients with established cardiovascular disease contains elevated levels of 3-chlorotyrosine and 3-nitrotyrosine, two characteristic products of MPO. When apolipoprotein A-I, the major HDL protein, was oxidized by MPO, its ability to promote cellular cholesterol was impaired. Moreover, oxidized apolipoprotein A-I was unable to activate LCAT, which rapidly converts free cholesterol to cholesteryl ester, a critical step in HDL maturation (Shao et al. 2010). Biochemical studies implicated tyrosine chlorination and methionine oxygenation in the loss of ability to promote cellular cholesterol efflux and LCAT activity by oxidized apolipoproteinA-I (Shao et al. 2008).

In animal studies, the existence of oxidized apolipoproteins has been described under several experimental models, i.e. in Watanabe heritable hyperlipidemic rabbits the occurrence of malondialdehyde-LDL and of autoantibodies against malondialdehyde-LDL has been reported (Haberland, Fong, \& Cheng 1988; Palinski et al. 1989). HDL from hypercholesterolemic chickens bear peroxidized oligomeric apolipoprotein A-I consequence of "in vivo" oxidation process (Artola et al. 1997). Interestingly, the oligomerization of apolipoprotein A-I implied dityrosine crosslink formation.

It was found that high-cholesterol diet increases formation of a potential marker of cardiac ONOO-, dityrosine in the perfusate, demonstrating that hyperlipidemia increases ONOOformation in the heart (Ónody et al. 2003). In contrast to dityrosine, perfusate nitrotyrosine was not statistically significantly increased in the study. This can be explained by results showing that at relatively low level of $\mathrm{ONOO}^{-}$, nitrotyrosine formation is suppressed in favor of dityrosine (Ónody et al. 2003).

Both the levels of dityrosine and Ne-(hexanonyl)lysine were significantly elevated in the kidneys of diabetic Akita mice compared with the control mice without any accumulation of thiobarbituric acid reactive substances and 4-hydroxy-2-nonenal-modified protein (Ueno et al. 2002). These findings are consistent with previous works showing that diabetes increases oxidized lipids and protein. In another model of diabetic mice, increased levels of dityrosine 
were found in the nerve of treated mice that had developed neuropathy respect to the control mice (Wiggin et al. 2008).

In one study, LDL oxidation and myocardial perfusion were measured in normocholesterolemic patients with type 1 diabetes before and after 4-month treatment with pravastatin or placebo. Pravastatin decreased LDL oxidation without improvement in myocardial perfusion reserve measured by positron emission tomography (Janatuinen et al. 2004).

\subsubsection{Pharmacological treatments with antioxidant effects}

The pathogenesis of chronic inflammatory diseases is regulated by modulation of the expression of redox-sensitive inflammatory genes including adhesion molecules, chemokines, cytokines and several receptors (Khatami 2009). The inflammation of vasculature produces reactive oxygen species (ROS) released both extracellularly from activated leukocytes as well as intracellularly in cells involved in the inflammatory reaction. ROS can be toxic and not only cause damage to biomolecules (DNA, proteins, lipids) but have been recognized as important intracellular signaling mediators (Nordberg \& Arnér 2001).

Besides vasculature system, free radicals are constantly produced in the brain "in vivo". Because of its high ATP demand, the brain consumes oxygen rapidly, and is thus susceptible to interference with mitochondrial function, which can in turn lead to increased superoxide radical formation (Zorov et al. 2006). Free radicals in central nervous system arise by the leakage of electrons from the mitochondrial electron transport chain to generate superoxide radical and are generated for precise purposes, such as the role of nitric oxide in neurotransmission and the production of superoxide radical by activated microglia (Breckwoldt et al. 2008).

Increased levels of oxidative damage to DNA, lipids and proteins have been detected by a range of assays in post-mortem tissues from patients with Parkinson's disease, Alzheimer's disease and amyotrophic lateral sclerosis, and at least some of these changes may occur early in disease progression (Ursini et al. 2002; Paula-Lima et al. 2009). The accumulation and precipitation of proteins that occur in these diseases may be aggravated by oxidative damage, and may in turn cause more oxidative damage by interfering with the function of the proteasome (Cook \& Petrucelli 2009). Indeed, it has been shown that proteasomal inhibition increases levels of oxidative damage to proteins and to other biomolecules. Hence, there are many attempts to develop antioxidants that can cross the blood-brain barrier and decrease oxidative damage (Halliwell 2007) and of biopharmaceuticals that can counteract protein oxidation and precipitation-aggregation (Wang 2005).

Aggregation of proteins is a common feature triggered by protein oxidation and it has been found "in vitro and "in vivo" being carbonylation a common feature (Mirzaei \& Regnier 2008). Aggregation is manifest in globular proteins, because under stress conditions or proteolysis nonnative conformations can be adopted. Although it seems that most proteins are able to form aggregates when expressed at high concentrations "in vitro", they differ substantially in their intrinsic propensity to do so "in vivo". The major contributors to aggregation propensity have been identified as hydrophobicity, net charge and propensity to form beta-sheet instead of alpha-helical structures (Tartaglia \& Caflisch 2007).

There is a large body of evidence demonstrating a role for ROS and oxidant stress in the pathogenesis of RA. Both preclinical and clinical studies have demonstrated relationship between oxidative stress biomarkers with disease progression and the potential beneficial 
effects of antioxidant supplementation or therapy (Uchida 2008). Although a complete understanding of how oxidative stress participates in the pathogenesis of RA is lacking, there is evidence demonstrating that expression of several inflammatory genes that participate in RA is regulated by redox-sensitive signaling pathways (Filippin et al. 2008).

Other cells that have an important role in inflammation are lymphocytes. Distinct types of lymphocytes have divergent effects of inflammation. For example; Tr1-type regulatory immune response cells (CD4CD25 T-cells) reduces the development of experimental atherosclerosis, while the activation of T-lymphocytes contributes importantly to atherogenesis (Mallat et al. 2003). In human atheroma, CD4-positive cells, the major T-cell population, appear to promote atherosclerosis through elaboration of proinflammatory cytokines, such as interferon (IFN), tumor necrosis factors (TNFs), and interleukin (IL)-2 (Zhou et al. 2000). In fact, patients with atherosclerosis and acute coronary syndromes exhibit T-cell activation and increased IFN serum levels (Liuzzo et al. 1999) and there is evidence that fibrates, drugs that are PPAR agonists, are anti-inflammatory mediators because they limit inflammatory cytokine expression of $T$ lymphocytes (Marx et al. 2002). Statins are currently the medical treatment of choice for hypercholesterolemia. In addition to attaining a decrease in serum cholesterol levels, statin therapy seems to promote other effects that are independent of changes in serum cholesterol. These "pleiotropic" effects include attenuation of vascular inflammation, improved endothelial cell function, stabilization of atherosclerotic plaque, decreased vascular smooth muscle cell migration and proliferation, and inhibition of platelet aggregation (Sadowitz et al. 2010) and increase the synthesis of apolipoprotein A-I and HDL biogenesis in the liver (Yamashita et al. 2010). Interestingly, statin therapy in dyslipidemic type 2 diabetic patients plays a protective role on the lipid and protein oxidative damage (Manfredini et al. 2010). We have tested the effect of a statin (atorvastatin) and of a fibrate (fenofibrate) on the activation of T lymphocytes in culture by an unspecific mitogen (concanavalin A). It was noted that upon activation with concanavalin A T-cells expressing IL-2 receptor (CD25, marker of activation) are augmented and that VLDL (very low density lipoprotein) inhibit the proportion of CD25+ CD4+ cells after $48 \mathrm{~h}$ of co-culturing. When lymphocytes were cultured with VLDL plus Atorvastatin CD25CD4 positive cells increased respect to cell culture with VLDL alone, suggesting that another anti-inflammatory effect of the statin (Forcato et al. 2007). In another study, it has been shown that the combined treatment of pravastatin with irbesartan reduced sPLA2-IIAactivity, sPLA2-IIA-protein concentration, and oxidized LDL in patients with CAD suggesting a novel anti-atherogenic effect by combining AT1-receptor blockade with statin treatment (Divchev et al. 2008).

Human hepatocyte cells in different cell cycle phases (G1 and G2/M) were analyzed using flow citometry techniques for VLDL receptor (VLDLR+). VLDLR+ cells belonged equally to cells in the quiescent and in the synthesis or mitosis phase of the cell cycle. Challenging them with lipopolysaccharide an increase in the percentage of VLDLR+ cells was produced. Gemfibrozil treatment decreased the number of resting VLDLR+ hepatocytes but increased significantly (more than twice) the number of VLDLR+ hepatocytes in phase G2/M (Forcato et al. 2007). These observations could explain why fenofibrate is particularly effective for reducing postprandial VLDL and LDL particle concentrations, and the increased oxidative stress and inflammatory response that occurs after a fatty meal (Rosenson 2008).

It is interesting to note that metabolites of statins and fenofibrate, but not the parent drugs, had been implied in protecting lipoproteins from oxidation "in vitro" suggesting that the antioxidant effects will be relevant "in vivo" (Aviram et al. 1998). 


\subsection{Oxidation of proteins in tissues and fluids, where there are good and bad neighbors}

In this section I pretend to discuss some new insights about reactions that occur only in complex milieu as the appearance of acrylamide (Stadler et al. 2004), the antioxidant activity of Maillard products (Yilmaz \& Toledo 2005) and discuss that some antioxidants produces oxidative modifications of proteins. Polyphenolic compounds have powerful antioxidant effects "in vitro" in many test systems, but can act as pro-oxidants in some others (Halliwell 2007). And it has been reported that tea catechins contribute to the formation of protein carbonyl in human serum albumin (HSA) (Ishii et al. 2010).

\subsubsection{Acrylamide from food is absorbed in humans}

The heating of free amino acids, in particular asparagine, and sugars during food processing $\left(120-180^{\circ} \mathrm{C}\right)$ results in the formation of acrylamide (Stadler et al. 2002). Most of the acrylamide ingested with food (i.e. fried potatoes) is absorbed in humans. Acrylamide and its metabolite glycidamide have the capability to bind covalently to the $-\mathrm{SH}$ and $-\mathrm{NH} 2$ groups of proteins and nucleic acid nitrogens. Although both acrylamide and glycidamide DNA adducts are formed "in vitro", only glycidamide adducts have been found after the administration of acrylamide or glycidamide "in vivo"(Gamboa da Costa et al. 2003). Acrylamide and glycidamide adducts to the NH2-terminal valine of human hemoglobin are used as convenient biomarkers for external acrylamide and/or internal glycidamide exposure. Acrylamide and glycidamide are also able to form glutathione conjugates that have been found in human urine, these metabolites have been proposed as biomarkers for acrylamide and glycidamide exposure (Fuhr et al. 2006). It is important to stress that there is no report of acrylamide formation in humans.

\subsubsection{Antioxidant activity of Maillard products}

Nonenzymatic glycation of free amino groups on proteins and amino acids is a biochemical reaction known as the "Maillard reaction." It has been proposed that this is an evolutionary pathway for labeling of senescent cellular proteins for their recognition and ultimate degradation. The two traditional factors found to modulate the early glycation of proteins are the concentration of glucose and half life of the protein, so in both major forms of diabetes, persistent hyperglycemia and oxidative stress act to increase the formation of advanced glycation end products (Reddy et al. 2009). But evidences in the literature have documented an increased glycated protein levels in some non-diabetic pathological states. Recently it has been hypothesized that oxidative stress either via increasing reactive oxygen species or by depleting the antioxidants may modulate the genesis of early glycated proteins "in vivo". This hypothesis was sustained by the observations that a common denominator in all non-diabetic pathological conditions is oxidative stress and that malondialdehyde, reduced glutathione, vitamin $\mathrm{C}$, vitamin $\mathrm{E}$ and drugs with antioxidant properties mitigate the process of protein glycation (Selvaraj et al. 2008). Maillard reactions occurring "in vivo" are associated with the chronic complications of diabetes mellitus and aging and age-related diseases by increases in oxidative chemical modification of lipids, DNA, and proteins. In particular, long-lived proteins such as lens, crystallines, collagens, and hemoglobin may react with reducing sugars to form advanced glycation end products and are biomarkers for detecting oxidative stress produced during Maillard reaction (Osawa \& Kato 2005).

The relationship between yin-yang and anti-oxidation-oxidation (Ou et al. 2003) seems also valid for Maillard reaction products since antioxidant activity of Maillard reaction products 
has been demonstrated "in vitro" in foods. The existence of this relationship "in vivo" will be a subject of research in the future since a few studies have been reported exploring the antioxidant capacity of Maillard reaction products using "in vivo" systems (Chen \& Kitts 2008).

\subsubsection{Oxidant activity of antioxidants}

Recent studies have reported that various polyphenolic compounds, including catechins, cause protein carbonyl formation in proteins via their pro-oxidant actions. The oxidation stability and binding affinity of catechins with proteins and with fatty acids bound to protein are responsible for the formation of protein carbonyl (Dufour et al. 2007). Polyphenol binding altered BSA conformation with a major reduction of alpha-helix and an increase in beta-sheet and turn structures, indicating a partial protein unfolding (Bourassa et al. 2007) that could increase BSA oxidation susceptibility. Some authors have claimed that antioxidants can stimulate oxidative damage "in vivo", especially ascorbate, alleged in several studies to increase oxidative DNA damage (Perron et al. 2011).

\subsubsection{Aggregation and proteolysis are defense or repair mechanisms?}

Moderately oxidized soluble cell proteins are selectively and rapidly degraded by the $20 \mathrm{~S}$ proteasome, while harshly oxidized, aggregated, and crosslinked proteins are poor substrates and actually inhibit the proteasome (Davies \& Shringarpure 2006). During aging, and in many age-related diseases/disorders, the proteasome is progressively inhibited by binding more protein aggregates. It has been postulated that an increase in the generation of reactive oxygen species as well as a decline in proteasome activity, results in the progressive accumulation of oxidatively damaged protein aggregates that eventually contribute to cellular dysfunction and senescence in senesce and disease (Davies \& Shringarpure 2006).

Small endogenous peptides, such as peptide hormones and signaling peptides, have strong effects on human. This has prompted an increasing interest from academia and food industries where it is reasoned that certain dietary peptides could also be potentially used as bioactive ingredients in functional foods. Dietary proteins have sequences of peptides, partially similar to those found in endogenous peptides, with hormonal or neuronal functions, and it has been proposed to exert physiological effects by acting either agonistically or antagonistically on the same targets as their endogenous counterparts (Ahlman \& Nilsson 2001). Scientists are currently exploring use of protein sources such as mammalian and fish meat, soybeans, chickpeas, almonds, etc. for production of bioactive peptides with different biological activities (Minkiewicz et al. 2011). Bioactive peptides can reduce free radicals and have antioxidant activity (Sarmadi \& Ismail 2010).

During protein oxidation aggregation and proteolysis occur simultaneaously, so it can be presumed that the balance between protein aggregation and antioxidant peptide generation is important in modulating inflammation "in vivo".

\subsection{Dityrosine and other markers of protein oxidative modification "in vivo"}

Most of the oxidative modifications that occurs "in vivo" and "in vitro" are susceptible of reversion and thus it is necessary to discern stable markers (Davies et al. 1999). Dityrosine bound formation and protein polymerization seems to be less prone to "in vivo" reduction or repair (Artola et al. 1997; Nagy et al. 2010). Also protein carbonyls could be a marker of endogenous oxidative stress (D'Aguanno et al. 2010), taking in account that this could be a 
better marker than dityrosine, when the oxidative stimulus is radiant energy (ultraviolet light) (Scheidegger et al. 2010).

\section{Conclusion}

\subsection{Is there a relationship between oxidized apolipoprotein and health status?}

Inflammation is associated with atherosclerosis. Human lipoproteins have been recognized to have proinflammatory or anti-inflammatory roles together with their receptors and the molecules involved in the interaction of lipoproteins with receptors. In example, it has been demonstrated that the inflammatory mediator IL-1ß disrupts cholesterol-mediated LDL receptor feedback regulation, permitting unregulated intracellular accumulation of unmodified LDL and causing foam cell formation. The authors suggest that this mechanism may contribute to the development of atherosclerosis in patients with chronic inflammation (Ruan et al. 2006).

On the other hand, the anti-atherogenic properties of HDL can be beneficial in metabolic diseases associated with accelerated atherosclerosis. Indeed, metabolic syndrome and type 2 diabetes are characterized by elevated cardiovascular risk and by low HDL-cholesterol (HDL-C) levels, but also by defective HDL function. Functional HDL deficiency is intimately associated with alterations in intravascular HDL metabolism and structure. Indeed, formation of HDL particles with attenuated antiatherogenic activity is mechanistically related to core lipid enrichment in triglycerides and cholesteryl ester depletion, altered apolipoprotein A-I conformation, replacement of apolipoprotein A-I by serum amyloid A, and covalent modification of HDL protein components by oxidation and glycation (Kontush \& Chapman 2006, 2010). "In vivo" oxidation of apolipoprotein-I is equally consistent with the observation that HDL from hypercholesterolemic chickens contain higher amounts of oligomeric apolipoprotein-I and are more susceptible to "in vitro" oxidation than HDL from control animals (Artola et al. 1997).

Fenofibrate is a PPAR- $\alpha$ agonist indicated for the treatment of hypertriglyceridemia and mixed dyslipidemia, lipid abnormalities commonly observed in patients at high risk of cardiovascular disease, including Type 2 diabetes and/or metabolic syndromes. Treatment with fenofibrate lowers triglycerides, raises HDL-cholesterol and decreases concentrations of small LDL-cholesterol particles and apolipoprotein B. Fenofibrate is effective for reducing postprandial VLDL and LDL particle concentrations that occurs after a fatty meal (Rosenson et al. 2007). This decrease in VLDL could be related to the increase in VLDL receptor cause by Gemfibrozil in spleen mononuclear cells, in human hepatocyte cells (HepG2) and in a human acute monocytic leukemia cell line (THP-1) cultured with the fibrate (Forcato 2008). Fibrate also produced an accumulation of apolipoprotein A-I in HepG2 (Forcato 2008). Thus it is probable that fibrates have several concurrent beneficial effects on hyperlipemia and oxidative imbalance.

The existence of oxidized lipids in pathological state is a common feature. Normal arteries contained similar levels of protein as atherosclerotic arteries, much less free cholesterol, and no detectable amounts of unoxidized or oxidized cholesteryl esters. It has been demonstrated the coexistence in human plaque of large amounts of oxidized cholesteryl esters with significant concentrations of ascorbate and vitamin $\mathrm{E}$ and that compared with healthy human arteries, advanced atherosclerotic plaques are not deficient in the antioxidant vitamins $\mathrm{C}$ and $\mathrm{E}$, despite the occurrence of massive lipid oxidation (Suarna et al. 1995). On the contrary the removal of oxidized phospholipid in normal cells is the norm. Oxidized phospholipids within LDL can promote phagocyte recognition and engulfment, even when present at only a few molecules 
per particle, by CD36, a prototypic member of the class B scavenger receptor family (Hazen 2008). The removal of oxidized lipids associated to lipoproteins or to membranes seems to grant a low level in physiological conditions.

\subsection{Damaged proteins are biomarkers of oxidation imbalance}

Damaged proteins are recognized by the proteolytic machinery for degradation to their constitutive amino acids; however, this process can be inefficient as is evidenced by their accumulation. Deposits of aggregated, misfolded, and oxidized proteins accumulate normally over time in cells and tissues, especially in postmitotic cells of the brain and heart, and are often present in increased amounts in a range of age-related disorders, such as atherosclerosis, neurodegeneration, and cataractogenesis (Dunlop et al. 2009; Dunlop Ra Fau - Rodgers et al. 2002).

Oxidatively modified proteins are usually considered degraded more or less exclusively by the proteasome system, although this would only apply to mildly oxidized proteins since substrates must be unfolded to enter the narrow catalytic chamber of the 20S core (Dunlop Ra Fau - Rodgers, Rodgers Kj Fau - Dean, \& Dean 2002).

Altogether, these studies show that protein oxidation products may serve as biomarkers for oxidative free radical damage. The intracellular accumulation of oxidized forms of proteins is a complex function of prooxidant-antioxidant activities and the concentrations and activities of the proteases that degrade the oxidized forms of proteins (Stadtman \& Levine 2000). However, measurements are performed in tissue or plasma that is invasively obtained samples. Therefore, future studies will have to be conducted to find techniques to determine these products in urine as well (de Zwart et al. 1999).

\section{Acknowledgment}

I thank Rolando Pascual Pecora, Gerardo Daniel Fidelio, María Cecilia Sampedro, Diego Oscar Forcato, Rodolfo Artola, Dana Scheidegger and Paola Radici for the joys and sorrows we shared. I thank Dr. Héctor Silvio Barra because he encouraged me to follow this topic of research. Grant support was from SeCyT, Universidad Nacional de Córdoba; Instituto de Investigación de la Universidad Nacional de Villa María, CONICET and MinCyT-Córdoba.

\section{References}

Ahlman, H., \& O. Nilsson. 2001. The gut as the largest endocrine organ in the body. Annals of Oncology 12 (suppl 2):S63-S68.

Allen, T. J., \& K. A. Jandeleit-Dahm. 2005. Preventing atherosclerosis with angiotensinconverting enzyme inhibitors: emphasis on diabetic atherosclerosis. Curr Drug Targets Cardiovasc Haematol Disord 5 (6):503-12.

Arai, H., \& K. Nakamura. 2004. Effect of L-ascorbic acid on the oxidative modification of apolipoprotein E in human very-low-density lipoprotein. J Nutr Sci Vitaminol (Tokyo) 50 (1):66-8.

Artola, R. L., C. B. Conde, L. Bagatolli, R. P. Pecora, G. D. Fidelio, \& S. C. Kivatinitz. 1997. High-density lipoprotein from hypercholesterolemic animals has peroxidized lipids and oligomeric apolipoprotein A-I: its putative role in atherogenesis. Biochem Biophys Res Commun 239 (2):570-4. 
Aviram, Michael, Mira Rosenblat, Charles L. Bisgaier, \& Roger S. Newton. 1998. Atorvastatin and gemfibrozil metabolites, but not the parent drugs, are potent antioxidants against lipoprotein oxidation. Atherosclerosis 138 (2):271-280.

Bassett, C. N., \& T. J. Montine. 2003. Lipoproteins and lipid peroxidation in Alzheimer's disease. J Nutr Health Aging 7 (1):24-9.

Batthyány, Carlos, Célio X. C. Santos, Horacio Botti, Carlos Cerveñansky, Rafael Radi, Ohara Augusto, \& Homero Rubbo. 2000. Direct Evidence for apo B-100-Mediated Copper Reduction: Studies with Purified apo B-100 and Detection of Tryptophanyl Radicals. Archives of Biochemistry and Biophysics 384 (2):335-340.

Bourassa, P., C. Kanakis, P. Tarantilis, M. G. Pollissiou, \& H. A. Tajmir-Riahi. 2007. Resveratrol, genistein, and curcumin bind bovine serum albumin. J Phys Chem B. 114 (9):6.

Breckwoldt, Michael O., John W. Chen, Lars Stangenberg, Elena Aikawa, Elisenda Rodriguez, Shumei Qiu, Michael A. Moskowitz, \& Ralph Weissleder. 2008. Tracking the inflammatory response in stroke in vivo by sensing the enzyme myeloperoxidase. Proceedings of the National Academy of Sciences 105 (47):18584-18589.

Candore, G., M. Bulati, C. Caruso, L. Castiglia, G. Colonna-Romano, D. Di Bona, G. Duro, D. Lio, D. Matranga, M. Pellicano, C. Rizzo, G. Scapagnini, \& S. Vasto. 2010. Inflammation, cytokines, immune response, apolipoprotein $\mathrm{E}$, cholesterol, and oxidative stress in Alzheimer disease: therapeutic implications. Rejuvenation Res 13 (2-3):301-13.

Cook, Casey, \& Leonard Petrucelli. 2009. A critical evaluation of the ubiquitin-proteasome system in Parkinson's disease. Biochimica et Biophysica Acta (BBA) - Molecular Basis of Disease 1792 (7):664-675.

Chantepie, S., E. Malle, W. Sattler, M. J. Chapman, \& A. Kontush. 2009. Distinct HDL subclasses present similar intrinsic susceptibility to oxidation by $\mathrm{HOCl}$. Arch Biochem Biophys 487 (1):28-35.

Chen, C. Y., P. E. Milbury, S. K. Chung, \& J. Blumberg. 2007. Effect of almond skin polyphenolics and quercetin on human LDL and apolipoprotein B-100 oxidation and conformation. J Nutr Biochem 18 (12):785-94.

Chen, Xiu-Min, \& David D. Kitts. 2008. Antioxidant Activity and Chemical Properties of Crude and Fractionated Maillard Reaction Products Derived from Four SugarAmino Acid Maillard Reaction Model Systems. Annals of the New York Academy of Sciences 1126 (1):220-224.

D'Aguanno, S., D. Franciotta, S. Lupisella, A. Barassi, D. Pieragostino, A. Lugaresi, D. Centonze, G. M. D'Eril, S. Bernardini, G. Federici, \& A. Urbani. 2010. Protein profiling of Guillain-Barre syndrome cerebrospinal fluid by two-dimensional electrophoresis and mass spectrometry. Neurosci Lett 485 (1):49-54.

Davies, Kelvin J.A., \& Reshma Shringarpure. 2006. Preferential degradation of oxidized proteins by the $20 \mathrm{~S}$ proteasome may be inhibited in aging and in inflammatory neuromuscular diseases. Neurology 66 (1 suppl 1):S93-S96.

Davies, Michael J., Shanlin Fu, Hongjie Wang, \& Roger T. Dean. 1999. Stable markers of oxidant damage to proteins and their application in the study of human disease. Free Radical Biology and Medicine 27 (11-12):1151-1163.

de Zwart, Loeckie L., John H. N. Meerman, Jan N. M. Commandeur, \& Nico P. E. Vermeulen. 1999. Biomarkers of free radical damage : Applications in experimental animals and in humans. Free Radical Biology and Medicine 26 (1-2):202-226. 
Deakin, S., I. Leviev, M. Gomaraschi, L. Calabresi, G. Franceschini, \& R. W. James. 2002. Enzymatically active paraoxonase- 1 is located at the external membrane of producing cells and released by a high affinity, saturable, desorption mechanism. J Biol Chem 277 (6):4301-8.

Divchev, Dimitar, Christina Grothusen, Maren Luchtefeld, Martin Thoenes, Frederick Onono, Rainer Koch, Helmut Drexler, \& Bernhard Schieffer. 2008. Impact of a combined treatment of angiotensin II type 1 receptor blockade and 3-hydroxy-3methyl-glutaryl-CoA-reductase inhibition on secretory phospholipase A2-type IIA and low density lipoprotein oxidation in patients with coronary artery disease. European Heart Journal 29 (16):1956-1965.

Dufour, C. , M. Loonis, \& O. Dangles. 2007. Inhibition of the peroxidation of linoleic acid by the flavonoid quercetin within their complex with human serum albumin. Free Radic Biol Med 43 (2):9.

Dunlop Ra Fau - Rodgers, Kenneth J., Roger T. Rodgers Kj Fau - Dean, \& R. T. Dean. 2002. Recent developments in the intracellular degradation of oxidized proteins. (08915849 (Print)).

Dunlop, Rachael A., Ulf T. Brunk, \& Kenneth J. Rodgers. 2009. Oxidized proteins: Mechanisms of removal and consequences of accumulation. IUBMB Life 61 (5):522527.

Edelstein, C., K. Nakajima, D. Pfaffinger, \& A. M. Scanu. 2001. Oxidative events cause degradation of apoB-100 but not of apo[a] and facilitate enzymatic cleavage of both proteins. J Lipid Res 42 (10):1664-70.

Erciyas, F., F. Taneli, B. Arslan, \& Y. Uslu. 2004. Glycemic control, oxidative stress, and lipid profile in children with type 1 diabetes mellitus. Arch Med Res 35 (2):134-40.

Filippin, L. I., R. Vercelino, N. P. Marroni, \& R. M. Xavier. 2008. Redox signalling and the inflammatory response in rheumatoid arthritis. Clinical \& Experimental Immunology 152 (3):415-422.

Forcato, Diego Oscar. 2008. Participación del receptor de VLDL en la producción de apolipoproteínas en hepatocitos humanos. Biochemistry, Química Biológica, Universidad Nacional de Córdoba, Córdoba.

Forcato, Diego Oscar, María Cecilia Sampedro, Rodolfo Artola, Rolando Pascual Pécora, \& Silvia Clara Kivatinitz. 2007. Respuesta del receptor de lipoproteína de muy baja densidad a estresores inflamatorios. Acta bioquímica clínica latinoamericana 41:483-490.

Fuhr, Uwe, Melanie I. Boettcher, Martina Kinzig-Schippers, Alexandra Weyer, Alexander Jetter, Andreas Lazar, Dirk Taubert, Dorota Tomalik-Scharte, Panagiota Pournara, Verena Jakob, Stefanie Harlfinger, Tobias Klaassen, Albrecht Berkessel, Jürgen Angerer, Fritz Sörgel, \& Edgar Schömig. 2006. Toxicokinetics of Acrylamide in Humans after Ingestion of a Defined Dose in a Test Meal to Improve Risk Assessment for Acrylamide Carcinogenicity. Cancer Epidemiology Biomarkers $\mathcal{E}$ Prevention 15 (2):266-271.

Gamboa da Costa, G., Mona I. Churchwell, L. Patrice Hamilton, Linda S. Von Tungeln, Frederick A. Beland, M. Matilde Marques, \& Daniel R. Doerge. 2003. DNA adduct formation from acrylamide via conversion to glycidamide in adult and neonatal mice. Chem Res Toxicol 16 (10):9.

Gao, X., S. Jayaraman, \& O. Gursky. 2008. Mild oxidation promotes and advanced oxidation impairs remodeling of human high-density lipoprotein in vitro. J Mol Biol 376 (4):997-1007. 
Gomes, L. F., L. M. Goncalves, F. L. Fonseca, C. M. Celli, L. A. Videla, H. Chaimovich, \& V. B. Junqueira. 2002. beta 2-glycoprotein I (apolipoprotein H) modulates uptake and endocytosis associated chemiluminescence in rat Kupffer cells. Free Radic Res 36 (7):741-7.

Haberland, ME, D Fong, \& L Cheng. 1988. Malondialdehyde-altered protein occurs in atheroma of Watanabe heritable hyperlipidemic rabbits. Science 241 (4862):215-218.

Halliwell, Barry. 2007. Dietary polyphenols: Good, bad, or indifferent for your health? Cardiovascular Research 73 (2):341-347.

Hazen, Stanley L. 2008. Oxidized Phospholipids as Endogenous Pattern Recognition Ligands in Innate Immunity. Journal of Biological Chemistry 283 (23):15527-15531.

Hedrick, C. C., S. R. Thorpe, M. X. Fu, C. M. Harper, J. Yoo, S. M. Kim, H. Wong, \& A. L. Peters. 2000. Glycation impairs high-density lipoprotein function. Diabetologia 43 (3):312-320.

Heinecke, Jay W. 2001. Is the Emperor Wearing Clothes?: Clinical Trials of Vitamin E and the LDL Oxidation Hypothesis. Arterioscler Thromb Vasc Biol 21 (8):1261-1264.

Hershfield, Michael S., L. Jackson Roberts, Nancy J. Ganson, Susan J. Kelly, Ines Santisteban, Edna Scarlett, Denise Jaggers, \& John S. Sundy. 2010. Treating gout with pegloticase, a PEGylated urate oxidase, provides insight into the importance of uric acid as an antioxidant in vivo. Proceedings of the National Academy of Sciences 107 (32):14351-14356.

Hillstrom, Robert J., Angela K. Yacapin-Ammons, \& Sean M. Lynch. 2003. Vitamin C Inhibits Lipid Oxidation in Human HDL. The Journal of Nutrition 133 (10):3047-3051.

Hockerstedt, Anna, Matti Jauhiainen, \& Matti J. Tikkanen. 2004. Lecithin/Cholesterol Acyltransferase Induces Estradiol Esterification in High-Density Lipoprotein, Increasing Its Antioxidant Potential. J Clin Endocrinol Metab 89 (10):5088-5093.

Ishii, Takeshi, Taiki Mori, Tatsuya Ichikawa, Maiko Kaku, Koji Kusaka, Yoshinori Uekusa, Mitsugu Akagawa, Yoshiyuki Aihara, Takumi Furuta, Toshiyuki Wakimoto, Toshiyuki Kan, \& Tsutomu Nakayama. 2010. Structural characteristics of green tea catechins for formation of protein carbonyl in human serum albumin. Bioorganic $\mathcal{E}$ Medicinal Chemistry 18 (14):4892-4896.

Janatuinen, Tuula, Juhani Knuuti, Jyri O. Toikka, Markku Ahotupa, Pirjo Nuutila, Tapani Ronnemaa, \& Olli T. Raitakari. 2004. Effect of Pravastatin on Low-Density Lipoprotein Oxidation and Myocardial Perfusion in Young Adults With Type 1 Diabetes. Arterioscler Thromb Vasc Biol 24 (7):1303-1308.

Jedidi, I., P. Therond, S. Zarev, C. Cosson, M. Couturier, C. Massot, D. Jore, M. GardesAlbert, A. Legrand, \& D. Bonnefont-Rousselot. 2003. Paradoxical protective effect of aminoguanidine toward low-density lipoprotein oxidation: inhibition of apolipoprotein B fragmentation without preventing its carbonylation. Mechanism of action of aminoguanidine. Biochemistry 42 (38):11356-65.

Jolivalt, C., B. Leininger-Muller, P. Bertrand, R. Herber, Y. Christen, \& G. Siest. 2000. Differential oxidation of apolipoprotein $\mathrm{E}$ isoforms and interaction with phospholipids. Free Radic Biol Med 28 (1):129-40.

Khatami, Mahin. 2009. Inflammation, Aging, and Cancer: Tumoricidal Versus Tumorigenesis of Immunity. Cell Biochemistry and Biophysics 55 (2):55-79.

Kontush, A., \& M. J. Chapman. 2006. Functionally defective high-density lipoprotein: a new therapeutic target at the crossroads of dyslipidemia, inflammation, and atherosclerosis. Pharmacol Rev 58 (3):342-74. 
Kontush, A., \& M. J. Chapman. 2010. Antiatherogenic function of HDL particle subpopulations: focus on antioxidative activities. Curr Opin Lipidol 21 (4):312-8.

Lawson, John A., Joshua Rokach, \& Garret A. FitzGerald. 1999. Isoprostanes: Formation, Analysis and Use As Indices of Lipid Peroxidation in Vivo. Journal of Biological Chemistry 274 (35):24441-24444.

Liuzzo, Giovanna, Stephen L. Kopecky, Robert L. Frye, W. Michael O' Fallon, Attilio Maseri, Jorg J. Goronzy, \& Cornelia M. Weyand. 1999. Perturbation of the T-Cell Repertoire in Patients With Unstable Angina. Circulation 100 (21):2135-2139.

Makedou, Kali G., Dimitri P. Mikhailidis, Areti Makedou, Stavros Iliadis, Anargyros Kourtis, Norma Vavatsi-Christaki, \& Georgios E. Papageorgiou. 2009. Lipid Profile, Low-Density Lipoprotein Oxidation and Ceruloplasmin in the Progeny of Families With a Positive History of Cardiovascular Diseases and/or Hyperlipidemia. Angiology 60 (4):455-461.

Mallat, Ziad, Andrea Gojova, Valerie Brun, Bruno Esposito, Nathalie Fournier, Francoise Cottrez, Alain Tedgui, \& Herve Groux. 2003. Induction of a Regulatory T Cell Type 1 Response Reduces the Development of Atherosclerosis in Apolipoprotein EKnockout Mice. Circulation 108 (10):1232-1237.

Manfredini, V., G. B. Biancini, C. S. Vanzin, A. M. Dal Vesco, C. A. Wayhs, C. Peralba Mdo, \& C. R. Vargas. 2010. Apolipoprotein, C-reactive protein and oxidative stress parameters in dyslipidemic type 2 diabetic patients treated or not with simvastatin. Arch Med Res 41 (2):104-9.

Marx, Nikolaus, Bettina Kehrle, Klaus Kohlhammer, Miriam Grub, Wolfgang Koenig, Vinzenz Hombach, Peter Libby, \& Jorge Plutzky. 2002. PPAR Activators as Antiinflammatory Mediators in Human $\mathrm{T}$ Lymphocytes: Implications for Atherosclerosis and Transplantation-Associated Arteriosclerosis. Circ Res 90 (6):703-710.

McIntyre, Thomas M., \& Stanley L. Hazen. 2010. Lipid Oxidation and Cardiovascular Disease: Introduction to a Review Series. Circ Res 107 (10):1167-1169.

Minkiewicz, P., J. Dziuba, \& J. Michalska. 2011. Bovine Meat Proteins as Potential Precursors of Biologically Active Peptides - a Computational Study based on the BIOPEP Database. Food Science and Technology International 17 (1):39-45.

Mirzaei, Hamid, \& Fred Regnier. 2008. Protein:protein aggregation induced by protein oxidation. Journal of Chromatography B 873 (1):8-14.

Moreno, J. A., F. Pérez-Jiménez, C. Marín, P. Gómez, P. Pérez-Martínez, R. Moreno, C. Bellido, F. Fuentes, \& J. López-Miranda. 2004. Apolipoprotein E gene promoter 219G->T polymorphism increases LDL-cholesterol concentrations and susceptibility to oxidation in response to a diet rich in saturated fat. The American Journal of Clinical Nutrition 80 (5):1404-1409.

Moreno, P. R., \& V. Fuster. 2004. New aspects in the pathogenesis of diabetic atherothrombosis. J Am Coll Cardiol 44 (12):2293-300.

Nagy, Emoke, John W. Eaton, Viktoria Jeney, Miguel P. Soares, Zsuzsa Varga, Zoltan Galajda, Jozsef Szentmiklosi, Gabor Mehes, Tamas Csonka, Ann Smith, Gregory M. Vercellotti, Gyorgy Balla, \& Jozsef Balla. 2010. Red Cells, Hemoglobin, Heme, Iron, and Atherogenesis. Arterioscler Thromb Vasc Biol 30 (7):1347-1353.

Nordberg, Jonas, \& Elias S. J. Arnér. 2001. Reactive oxygen species, antioxidants, and the mammalian thioredoxin system. Free Radical Biology and Medicine 31 (11):1287-1312. 
Obama, T., R. Kato, Y. Masuda, K. Takahashi, T. Aiuchi, \& H. Itabe. 2007. Analysis of modified apolipoprotein B-100 structures formed in oxidized low-density lipoprotein using LC-MS/MS. Proteomics 7 (13):2132-41.

Ónody, Annamária, Csaba Csonka, Zoltán Giricz, \& Péter Ferdinandy. 2003. Hyperlipidemia induced by a cholesterol-rich diet leads to enhanced peroxynitrite formation in rat hearts. Cardiovascular Research 58 (3):663-670.

Osawa, Toshihiko, \& Yoji Kato. 2005. Protective Role of Antioxidative Food Factors in Oxidative Stress Caused by Hyperglycemia. Annals of the New York Academy of Sciences 1043 (1):440-451.

Ou, Boxin, Dejian Huang, Maureen Hampsch-Woodill, \& Judith A. Flanagan. 2003. When east meets west: the relationship between yin-yang and antioxidation-oxidation. The FASEB Journal 17 (2):127-129.

Palinski, W, M E Rosenfeld, S Ylä-Herttuala, G C Gurtner, S S Socher, S W Butler, S Parthasarathy, T E Carew, D Steinberg, \& J L Witztum. 1989. Low density lipoprotein undergoes oxidative modification in vivo. Proceedings of the National Academy of Sciences 86 (4):1372-1376.

Patterson, Rebecca A., Elizabeth T. M. Horsley, \& David S. Leake. 2003. Prooxidant and antioxidant properties of human serum ultrafiltrates toward LDL. Journal of Lipid Research 44 (3):512-521.

Paula-Lima, A. C., M. A. Tricerri, J. Brito-Moreira, T. R. Bomfim, F. F. Oliveira, M. H. Magdesian, L. T. Grinberg, R. Panizzutti, \& S. T. Ferreira. 2009. Human apolipoprotein A-I binds amyloid-beta and prevents Abeta-induced neurotoxicity. Int J Biochem Cell Biol 41 (6):1361-70.

Perron, N. R. , Carla R. Garcia, Julio R. Pinzon, Manuel N. Chaur, \& Julia L. Brumaghim. 2011. Antioxidant and prooxidant effects of polyphenol compounds on coppermediated DNA damage. J Inorg Biochem. 105 (5):745.

Popa, C, L J H van Tits, P Barrera, H L M Lemmers, F H J van den Hoogen, P L C M van Riel, T R D J Radstake, M G Netea, M Roest, \& A F H Stalenhoef. 2009. Antiinflammatory therapy with tumour necrosis factor alpha inhibitors improves highdensity lipoprotein cholesterol antioxidative capacity in rheumatoid arthritis patients. Annals of the Rheumatic Diseases 68 (6):868-872.

Reddy, V. Prakash, Xiongwei Zhu, George Perry, \& Mark A. Smith. 2009. Oxidative Stress in Diabetes and Alzheimer's Disease. Journal of Alzheimer's Disease 16 (4):763-774.

Roland, Alexander, Rebecca A. Patterson, \& David S. Leake. 2001. Measurement of CopperBinding Sites on Low Density Lipoprotein. Arterioscler Thromb Vasc Biol 21 (4):594-602.

Rosenson, R. S. 2008. Fenofibrate: treatment of hyperlipidemia and beyond. Expert Rev Cardiovasc Ther 6 (10):1319-30.

Rosenson, Robert S., David A. Wolff, Anna L. Huskin, Irene B. Helenowski, \& Alfred W. Rademaker. 2007. Fenofibrate Therapy Ameliorates Fasting and Postprandial Lipoproteinemia, Oxidative Stress, and the Inflammatory Response in Subjects With Hypertriglyceridemia and the Metabolic Syndrome. Diabetes Care 30 (8):1945-1951.

Ruan, Xiong Z., John F. Moorhead, Jian L. Tao, Kun L. Ma, David C. Wheeler, Stephen H. Powis, \& Zac Varghese. 2006. Mechanisms of Dysregulation of Low-Density Lipoprotein Receptor Expression in Vascular Smooth Muscle Cells by Inflammatory Cytokines. Arterioscler Thromb Vasc Biol 26 (5):1150-1155.

Sadowitz, Benjamin, Kristopher G. Maier, \& Vivian Gahtan. 2010. Basic Science Review: Statin Therapy-Part I: The Pleiotropic Effects of Statins in Cardiovascular Disease. Vascular and Endovascular Surgery 44 (4):241-251. 
Sarmadi, B. H., \& Amin Ismail. 2010. Antioxidative peptides from food proteins: a review. Peptides 31 (10):7.

Scheidegger, D., R. P. Pecora, P. M. Radici, \& S. C. Kivatinitz. 2010. Protein oxidative changes in whole and skim milk after ultraviolet or fluorescent light exposure. $J$ Dairy Sci 93 (11):5101-9.

Selvaraj, N., Z. Bobby, \& M. G. Sridhar. 2008. Oxidative stress: Does it play a role in the genesis of early glycated proteins? Medical hypotheses 70 (2):265-268.

Seshadri, Vasudevan, Paul L. Fox, \& Chinmay K. Mukhopadhyay. 2002. Dual Role of Insulin in Transcriptional Regulation of the Acute Phase Reactant Ceruloplasmin. Journal of Biological Chemistry 277 (31):27903-27911.

Shao, B., M. N. Oda, J. F. Oram, \& J. W. Heinecke. 2010. Myeloperoxidase: an oxidative pathway for generating dysfunctional high-density lipoprotein. Chem Res Toxicol 23 (3):447-54.

Shao, Baohai, Giorgio Cavigiolio, Nathan Brot, Michael N. Oda, \& Jay W. Heinecke. 2008. Methionine oxidation impairs reverse cholesterol transport by apolipoprotein A-I. Proceedings of the National Academy of Sciences 105 (34):12224-12229.

Sigalov, A. B., \& L. J. Stern. 2001. Oxidation of methionine residues affects the structure and stability of apolipoprotein A-I in reconstituted high density lipoprotein particles. Chem Phys Lipids 113 (1-2):133-46.

Stadler, Richard H., Imre Blank, Natalia Varga, Fabien Robert, Jorg Hau, Philippe A. Guy, Marie-Claude Robert, \& Sonja Riediker. 2002. Food chemistry: Acrylamide from Maillard reaction products. Nature 419 (6906):449-450.

Stadler, Richard H., Fabien Robert, Sonja Riediker, Natalia Varga, Tomas Davidek, Stéphanie Devaud, Till Goldmann, Jörg Hau, \& Imre Blank. 2004. In-Depth Mechanistic Study on the Formation of Acrylamide and Other Vinylogous Compounds by the Maillard Reaction. Journal of Agricultural and Food Chemistry 52 (17):5550-5558.

Stadtman, Earl R., \& Rodney L. Levine. 2000. Protein Oxidation. Annals of the New York Academy of Sciences 899 (1):191-208.

Suarna, Cacang, Roger T. Dean, James May, \& Roland Stocker. 1995. Human Atherosclerotic Plaque Contains Both Oxidized Lipids and Relatively Large Amounts of \{alpha\}Tocopherol and Ascorbate. Arterioscler Thromb Vasc Biol 15 (10):1616-1624.

Suc, Isabelle, Sylvain Brunet, Grant Mitchell, Georges-Etienne Rivard, \& Emile Levy. 2003. Oxidative tyrosylation of high density lipoproteins impairs cholesterol efflux from mouse J774 macrophages: role of scavenger receptors, classes A and B. J Cell Sci 116 (1):89-99.

Tartaglia, Gian Gaetano, \& Amedeo Caflisch. 2007. Computational analysis of the S. cerevisiae proteome reveals the function and cellular localization of the least and most amyloidogenic proteins. Proteins: Structure, Function, and Bioinformatics 68 (1):273-278.

Uchida, K. 2008. A lipid-derived endogenous inducer of COX-2: a bridge between inflammation and oxidative stress. Mol Cells 25 (3):347-51.

Ueno, Yuki, Fumihiko Horio, Koji Uchida, Michitaka Naito, Hideki Nomura, Yoji Kato, Takanori Tsuda, Shinya Toyokuni, \& Toshihiko Osawa. 2002. Increase in Oxidative Stress in Kidneys of Diabetic Akita Mice. Bioscience, Biotechnology, and Biochemistry 66 (4):869-872.

Ursini, Fulvio, Kelvin J. A. Davies, Matilde Maiorino, Tiziana Parasassi, \& Alex Sevanian. 2002. Atherosclerosis: another protein misfolding disease? Trends in Molecular Medicine 8 (8):370-374. 
Van Antwerpen, P., K. Z. Boudjeltia, S. Babar, I. Legssyer, P. Moreau, N. Moguilevsky, M. Vanhaeverbeek, J. Ducobu, \& J. Neve. 2005. Thiol-containing molecules interact with the myeloperoxidase/H2O2/chloride system to inhibit LDL oxidation. Biochem Biophys Res Commun 337 (1):82-8.

Van Antwerpen, P., I. Legssyer, K. Zouaoui Boudjeltia, S. Babar, P. Moreau, N. Moguilevsky, M. Vanhaeverbeek, J. Ducobu, \& J. Neve. 2006. Captopril inhibits the oxidative modification of apolipoprotein B-100 caused by myeloperoxydase in a comparative in vitro assay of angiotensin converting enzyme inhibitors. Eur J Pharmacol 537 (1-3):31-6.

Wang, Wei. 2005. Protein aggregation and its inhibition in biopharmaceutics. International Journal of Pharmaceutics 289 (1-2):1-30.

Wiggin, Timothy D., Matthias Kretzler, Subramaniam Pennathur, Kelli A. Sullivan, Frank C. Brosius, \& Eva L. Feldman. 2008. Rosiglitazone Treatment Reduces Diabetic Neuropathy in Streptozotocin-Treated DBA/2J Mice. Endocrinology 149 (10):4928-4937.

Yamashita, S., K. Tsubakio-Yamamoto, T. Ohama, Y. Nakagawa-Toyama, \& M. Nishida. 2010. Molecular mechanisms of HDL-cholesterol elevation by statins and its effects on HDL functions. J Atheroscler Thromb 17 (5):436-51.

Yang, Chao-Yuh, Zi-Wei Gu, Hui-Xin Yang, Manlan Yang, Antonio M. Gotto, \& Charles V. Smith. 1997. Oxidative Modifications of APOB-100 by Exposure of Low Density Lipoproteins to HOCl In Vitro. Free Radical Biology and Medicine 23 (1):82-89.

Yilmaz, Yusuf, \& Romeo Toledo. 2005. Antioxidant activity of water-soluble Maillard reaction products. Food Chemistry 93 (2):273-278.

Yoshida, Hiroshi, \& Reiko Kisugi. 2010. Mechanisms of LDL oxidation. Clinica Chimica Acta 411 (23-24):1875-1882.

Yuan, Quan, Xiaochun Zhu, \& Lawrence M. Sayre. 2006. Chemical Nature of Stochastic Generation of Protein-based Carbonyls: Metal-catalyzed Oxidation versus Modification by Products of Lipid Oxidationt. Chemical Research in Toxicology 20 (1):129-139.

Zarev, S., D. Bonnefont-Rousselot, C. Cosson, J. L. Beaudeux, J. Delattre, M. Gardes-Albert, A. Legrand, \& P. Therond. 2002. In vitro low-density lipoprotein oxidation by copper or ${ }^{*} \mathrm{OH} / \mathrm{O}^{*}(2)(-)$ : new features on carbonylation and fragmentation of apolipoprotein B during the lag phase. Arch Biochem Biophys 404 (1):10-7.

Zhang, Renliang, Marie-Luise Brennan, Zhongzhou Shen, Jennifer C. MacPherson, Dave Schmitt, Cheryl E. Molenda, \& Stanley L. Hazen. 2002. Myeloperoxidase Functions as a Major Enzymatic Catalyst for Initiation of Lipid Peroxidation at Sites of Inflammation. Journal of Biological Chemistry 277 (48):46116-46122.

Zhou, Xinghua, Antonino Nicoletti, Rima Elhage, \& Goran K. Hansson. 2000. Transfer of CD4+ T Cells Aggravates Atherosclerosis in Immunodeficient Apolipoprotein E Knockout Mice. Circulation 102 (24):2919-2922.

Zorov, Dmitry B., Magdalena Juhaszova, \& Steven J. Sollott. 2006. Mitochondrial ROSinduced ROS release: An update and review. Biochimica et Biophysica Acta (BBA) Bioenergetics 1757 (5-6):509-517. 


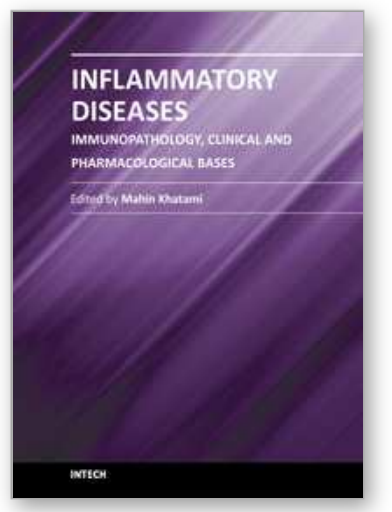

\author{
Inflammatory Diseases - Immunopathology, Clinical and \\ Pharmacological Bases \\ Edited by Dr Mahin Khatami
}

ISBN 978-953-307-911-0

Hard cover, 396 pages

Publisher InTech

Published online 10, February, 2012

Published in print edition February, 2012

This book is a collection of comprehensive reviews contributed by experts in the diverse fields of acute and chronic inflammatory diseases, with emphasis on current pharmacological and diagnostic options. Interested professionals are also encouraged to review the contributions made by experts in a second related book entitled "Inflammation, Chronic Diseases and Cancer"; it deals with immunobiology, clinical reviews, and perspectives of the mechanisms of immune inflammatory responses that are involved in alterations of immune dynamics during the genesis, progression and manifestation of a number of inflammatory diseases and cancers, as well as perspectives for diagnosis, and treatment or prevention of these disabling and potentially preventable diseases, particularly for the growing population of older adults around the globe.

\title{
How to reference
}

In order to correctly reference this scholarly work, feel free to copy and paste the following:

Silvia Clara Kivatinitz (2012). Relationship Between Protein Oxidation Markers and Oxidative Stress Biomarkers, Inflammatory Diseases - Immunopathology, Clinical and Pharmacological Bases, Dr Mahin Khatami (Ed.), ISBN: 978-953-307-911-0, InTech, Available from:

http://www.intechopen.com/books/inflammatory-diseases-immunopathology-clinical-and-pharmacologicalbases/relationship-between-protein-oxidation-markers-and-oxidative-stress-biomarkers

\section{INTECH}

open science | open minds

\author{
InTech Europe \\ University Campus STeP Ri \\ Slavka Krautzeka 83/A \\ 51000 Rijeka, Croatia \\ Phone: +385 (51) 770447 \\ Fax: +385 (51) 686166 \\ www.intechopen.com
}

\author{
InTech China \\ Unit 405, Office Block, Hotel Equatorial Shanghai \\ No.65, Yan An Road (West), Shanghai, 200040, China \\ 中国上海市延安西路65号上海国际贵都大饭店办公楼 405 单元 \\ Phone: +86-21-62489820 \\ Fax: +86-21-62489821
}


(C) 2012 The Author(s). Licensee IntechOpen. This is an open access article distributed under the terms of the Creative Commons Attribution 3.0 License, which permits unrestricted use, distribution, and reproduction in any medium, provided the original work is properly cited. 